\title{
Pengaruh Senam Prolanis Terhadap Pengendalian Kadar Glukosa Darah dan Tekanan Darah Pada Pasien Diabetes Melitus Tipe II dan Hipertensi
}

\author{
Ivonna Hasfika (1) , Suci Erawati (2) , Friska Ernita Sitorus (3) \\ Institut Kesehatan Deli Husada Deli Tua \\ hasfikaivonna@yahoo.co.id, esuci64@gmail.com, friskasitorus87@gmail.com
}

\begin{abstract}
ABSTRAK
Diabetes Mellitus - Hipertensi (DM-HT) adalah intoleransi karbohidrat yang ditandai dengan resistensi insulin, defisiensi insulin relatif, produksi glukosa berlebih oleh hati dan hiperglikemia. Diabetes dan komplikasinya membawa kerugian besar bagi penderita diabetes dan keluarga. Upaya yang dilakukan untuk mengendalikannya adalah dengan latihan prolanis. Tujuan penelitian ini untuk mengetahui pengaruh senam prolanis terhadap tekanan darah dan pengendalian kadar glukosa darah pada pasien DM Tipe II dan Hipertensi di Puskesmas Aek Habil Sibolga. Jenis penelitian dengan menggunakan one group pre and post test dimana penelitiannya terdapat pretest sebelum diberi perlakuan dan posttest setelah diberi perlakuan. Populasi dalam penelitian ini adalah seluruh penderita diabetes tipe II dan hipertensi di wilayah kerja Puskesmas Aek Habil dengan jumlah sampel sebanyak 49 orang yang diambil dengan teknik purposive sampling. Analisis data menggunakan Paired t-test. Sebelum dianalisis dilakukan uji normalitas data terlebih dahulu dimana diperoleh hasil untuk data kadar gula darah terdistribusi normal dan untuk data tekanan darah sistol dan diastol tidak berdistribusi normal. Berdasarkan hasil penelitian terdapat pengaruh senam prolanis terhadap gula darah dengan signifikansi 0,001. Pada tekanan darah didapatkan hasil ada pengaruh senam prolanis terhadap perubahan tekanan darah sistol dengan signifikansi 0,000, dan tekanan darah diastol dengan signifikansi 0,00. Dari hasil penelitian dapat disimpulkan bahwa terdapat pengaruh Senam Prolanis terhadap pengendalian kadar gula darah dan tekanan darah pada penderita Diabetes Mellitus dan Hipertensi. Diharapkan kepada tenaga kesehatan dapat meningkatkan upaya penanganan penyakit diabetes melitus dengan mengoptimalkan kegiatan senam prolanis.
\end{abstract}

Kata Kunci : Latihan Prolanis, Tekanan Darah, Kadar Glukosa Darah

\begin{abstract}
Diabetes Mellitus - Hypertension (DM-HT) is carbohydrate intolerance marked with insulin resistance, relative insulin deficiency, excess glucose production by the liver and hyperglycemia. Diabetes and its complications bring huge losses for diabetics and families. Efforts made to control it is with prolanist exercises. The purpose of this research to find out the influence of prolanist gymnastics against blood pressure and controlling blood glucose levels in Patients with Type II DM and Hypertension at Puskesmas Aek Habil Sibolga. Types of research by using one group pre and post test where is the research there is a pretest before being treated and posttest after being treated. The population in this study is all people with Type II diabetes and hypertension in the working area of the Aek Habil Health Center with the number of samples as many as 49 people taken with a purposive sampling technique. Data analysed by using Paired t-test. Before being analysed done first data normality test where results are obtained for blood sugar levels distributed data normally and for systole blood pressure and diastole data is not normally distributed. Based on research results there was the influence of prolanist exercises with blood sugar with significancy 0,001 . On blood pressure is obtained the results there is the influence of prolanist gymnastics against changes in systole blood pressure with significancy 0,000 , and diastole blood pressure with significancy 0,00 . From the results of the study can be concluded that there is the influence of Prolanist Gymnastics on controlling blood sugar levels and blood pressure in people with Diabetes Mellitus and hypertension. Expected to health workers to increase disease management efforts diabetes mellitus by optimizing prolanist gymnastics activities.
\end{abstract}

Keywords : Prolanist Exercises, Blood Pressure, Blood Glucose Levels 
Hasfika Ivonna, Erawati S, Sitorus Friska E : Pengaruh Senam Prolanis Terhadap Pengendalian Kadar Glukosa Darah dan Tekanan Darah Pada Pasien Diabetes Melitus Tipe II dan Hipertensi

\section{PENDAHULUAN}

\section{Latar Belakang}

Menurut Badan Kesehatan Dunia WHO (2018), kematian yang diakibatkan oleh Penyakit Tidak Menular (PTM) diperkirakan terus mengalami peningkatan di seluruh dunia. Peningkatan yang terbesar akan terjadi di negara- menengah dan miskin. Lebih dari dua pertiga dari seluruh penduduk global akan meninggal karena disebabkan oleh penyakit tidak menular misalnya kanker, penyakit jantung, stroke juga diabetes. Jika ditotalkan pada tahun 2030 diprediksi akan ada sebanyak 52 juta jiwa kematian per tahun yang disebebakan oleh penyakit tidak menular. Dari semua kasus 90 - 95\% merupakan Diabetes MellitusHipertensi (Depkes RI, 2015). Diabetes Mellitus - Hypertensi (DM-HT) adalah intoleransi karbohidrat yang memberikan tanda misalnya resisten terhadap insulin, penurunan relatif insulin, glukosa yang berlebih oleh hepar dan hiperglikemia (Brasher, 2007). Kematian akibat DM-HT dari tahun ke tahun akan selalu terjadi peningkatan. Pada tahun 2014 kematian akibat diabetes mellitus sebanyak 37 orang, tahun 2015 sebanyak 180 orang dan pada tahun 2016 menigkat menjadi 237 orang (DKK Semarang, 2017). Hal ini memperlihatkan bahwa pengendalian Diabetes Mellitus-Hypertensi (DM-HT) yang dilakukan oleh penderita belum optimal sehingga perlu mendapatkan pelayanan kesehatan prioritas. Secara umum diketahui bahwa prinsip pengendalian serta penanganan Diabetes Mellitus antara lain pengaturan makan (diet), latihan jasmani, perubahan perilaku, dan konsumsi obat antidiabetik (Bustan, 2007). Menurut Hordern (2012) olahraga yang dianjurkan pada penderita DM adalah aerobic low impact dan rithmis, antara lain berenang, jogging, naik sepeda, dan senam, karena diharapkan mampu menggunakan semua otot- otot besar, pernapasan serta jantung.

\section{Perumusan Masalah}

Perlu diperhatikan bahwa olahraga kesehatan adalah gerak olahraga yang sesuai dengan takaran sedang, bukan dengan olahraga berat. Selain diberikan pada penderita DM Tipe II, olahraga juga sangat sering diberikan pada penderita yang mengalami hipertensi yaitu olahrga aerobik. Banyak bentuk-bentuk olahraga aerobik yang dapat dilakukan oleh pasien hipertensi yaitu jogging dan senam aerobic.

\section{Tujuan Penelitian}

Olahraga yang teratur mampu menurunkan tekanan sistolik maupun diastolik pada orang dengan hipertensi tingkat ringan. Upaya yang dilakukan oleh pemerintah bersama dengan Badan Penyelenggara Jaminan Sosial Kesehatan (BPJS) untuk mengendalikan PTM yaitu dengan membuat suatu program untuk pengelolaan penyakit kronis yang diberi nama akronim prolanis (Program Pengelolaan Penyakit Kronis).

\section{Manfaat Penelitian}

Prolanis merupakan suatu sistem pelayanan kesehatan dan pendekatan proaktif yang dilaksanakan secara terintegrasi yang melibatkan peserta, fasilitas kesehatan dan BPJS Kesehatan dalam rangka pemeliharaan kesehatan bagi peserta BPJS kesehatan yang menderita penyakit kronis untuk mencapai kualitas hidup yang optimal dengan biaya kesehatan yang efektif dan efisien (BPJS Kesehatan, 2014).

\section{METODE PENELITIAN}

\section{Tempat dan Waktu Penelitian}

Penelitian ini akan dilaksanakan di Puskesmas Aek Habil, Kecamatan Sibolga Selatan, Kota Sibolga.. 
Hasfika Ivonna, Erawati S, Sitorus Friska E : Pengaruh Senam Prolanis Terhadap Pengendalian Kadar Glukosa Darah dan Tekanan Darah Pada Pasien Diabetes Melitus Tipe II dan Hipertensi

\section{Alat dan Bahan Penelitian}

Alat yang digunakan pada penelitian adalah alat pengukur hipertensi (denyut jantung) dan counter (alat penghitung).

\section{Populasi dan Sampel}

Adapun target populasi yang diharapkan pada penelitian ini adalah seluruh penyandang DM Tipe II dan Hipertensi. Teknik penarikan sampel yang dijadikan responden pada penelitian ini adalah Purposive Sampling dengan criteria Penyandang DM Tipe II dan Hipertensi yang sudah mengalami sakit $\geq 2$ tahun, usia 45-55 tahun, Penyandang DM Tipe II dan Hipertensi berdasarkan diagnosa dokter. Besar sampel dalam penelitian ini diperoleh sebanyak 49 responden. Data dianalisis dengan menggunakan Uji t-test berpasangan (Paired sample ttest).

\section{HASIL}

\section{Hasil dan Pembahasan}

Tabel 1. Karakteristik Responden

\begin{tabular}{|l|l|l|}
\hline Karakteristik & $\mathbf{f}$ & $\%$ \\
\hline Pendidikan & & \\
\hline 1. Tidak Sekolah - SD & 3 & 6,1 \\
\hline 2. SLTP & 18 & 36,7 \\
\hline 3. SMU & 26 & 53,1 \\
\hline 4. PT & 2 & 4,1 \\
\hline Lama Menderita DM & & \\
\hline 1. <5 Tahun & 6 & 12,2 \\
\hline 2. $\geq 5$ Tahun & 43 & 87,8 \\
\hline Usia & & \\
\hline Mean & 59,8 & \\
\hline SD & 4,5 & \\
\hline Minimum & 50 & \\
\hline Maksimum & 72 & $\mathbf{1 0 0}$ \\
\hline Total & $\mathbf{4 9}$ & \\
\hline
\end{tabular}

Berdasarkan hasil penelitian diketahui mayoritas pendidikan responden adalah SMU yaitu 53,1\% dan minoritas adalah Tidak Sekolah-SD yaitu 6,1\%. Berdasarkan Lama menderita $\mathrm{DM}$ responden mayoritas menderita $\mathrm{DM} \geq 5$ Tahun dan rata-rata usia responden adalah 59,8 dengan usia minimum 50 tahun dan usia maksimum 72 tahun.

Tabel 2. Distribusi KGD dan Tekanan Darah Pre-Post test

\begin{tabular}{|l|l|l|l|l|}
\hline Variabel & Mean & S.D & Min & Max \\
\hline $\begin{array}{l}\text { KGD } \\
\text { Pre-test }\end{array}$ & 235,29 & 12,6 & 207 & 260 \\
\hline $\begin{array}{l}\text { KGD } \\
\text { ost-test }\end{array}$ & 229,37 & 14,6 & 180 & 260 \\
\hline $\begin{array}{l}\text { TD Sistol } \\
\text { Pre-test }\end{array}$ & 151,18 & 6,9 & 140 & 167 \\
\hline $\begin{array}{l}\text { D Sistol } \\
\text { ost-test }\end{array}$ & 147,51 & 6,8 & 120 & 160 \\
\hline
\end{tabular}


Hasfika Ivonna, Erawati S, Sitorus Friska E : Pengaruh Senam Prolanis Terhadap Pengendalian Kadar Glukosa Darah dan Tekanan Darah Pada Pasien Diabetes Melitus Tipe II dan Hipertensi

\begin{tabular}{|l|l|l|l|l|}
\hline $\begin{array}{l}\text { TD Diastol } \\
\text { Pre-test }\end{array}$ & 97,39 & 4,82 & 90 & 110 \\
\hline $\begin{array}{l}\text { D Diastol } \\
\text { ost-test }\end{array}$ & 89,04 & 4,89 & 80 & 100 \\
\hline
\end{tabular}

Berdasarkan hasil penelitian pada Tabel diatas diketahui bahwa rata-rata KGD sebelum diberikan senam prolanis adalah 235,29 mq/dl, dan rata-rata KGD setelah diberikan senam prolanis adalah 229,37 mq/dl, rata-rata tekanan darah sistol sebelum diberikan senam prolanis adalah $151,18 \mathrm{mmHg}$, dan rata-rata tekanan darah sistol setelah diberikan senam prolanis adalah 147,51 $\mathrm{mmHg}$. Tekanan darah Diastol sebelum diberikan senam prolanis adalah $97,39 \mathrm{mmHg}$, dan rata-rata tekanan darah diastol setelah diberikan senam prolanis adalah $89,04 \mathrm{mmHg}$.

Tabel 3. Uji Normalitas Data

\begin{tabular}{|l|c|l|}
\hline \multicolumn{1}{|c|}{ Variabel } & Sig. & Kesimpulan \\
\hline KGD Pre Test &, 371 & Normal \\
\hline KGD Post-Tes &, 111 & Normal \\
\hline TD Sistol Pre-Test &, 030 & Tidak Normal \\
\hline TD Sistol Post-Tes &, 000 & Tidak Normal \\
\hline TD Diatol Pre Test &, 000 & Tidak Normal \\
\hline TD Diastol Post-Tes &, 000 & Tidak Normal \\
\hline
\end{tabular}

Berdasarkan tabel diatas diketahui bahwa berdasarkan uji normalitas data dengan menggunakan Shapiro-wilk diketahui bahwa KGD pre dan Post test berada pada rentang normal yaitu 0,371 dan $0,111(\geq 0,05)$. Sedangkan TD sistol dan diastol berdistribusi tidak normal dimana nilai $\mathrm{p}$ berada dibawah 0,05 . Berdasarkan hasil diatas maka dapat diketahui bahwa uji statistic yang digunakan pada KGD adalah dengan menggunakan uji paired t-test, sedangkan untuk uji statistic TD sistol dan diastole dengan menggunakan uji Wilcoxon rank test.

Tabel 4. Pengaruh Senam Prolanis terhadap KGD

\begin{tabular}{|l|l|l|l|l|}
\hline KGD & $\begin{array}{l}\text { Mean } \\
\text { Difference }\end{array}$ & S.D & $t$ & Sig \\
\hline $\begin{array}{l}\text { Pre-Test } \\
\text { Post-Test }\end{array}$ & 5.918 & 11.5 & 3,587 &, 001 \\
\hline
\end{tabular}

Berdasarkan hasil penelitian didapatkan bahwa rata-rata penurunan KGD adalah 5,918 mq/dl dengan SD 11,549. Dan diapatkan juga bahwa terdapat pengaruh senam prolanis dnegan perubahan KGD dimana didapatkan hasil p-value 0,001 yaitu $<0,05$.

Tabel 5. Pengaruh Senam Prolanis terhadap TD Sistol

\begin{tabular}{|l|l|l|l|}
\hline TD Sistol & Mean Difference & $\mathrm{Z}$ & Sig \\
\hline Pre-Test & 22.23 & $-3,276$ &, 001 \\
Post-Test & & & \\
\hline
\end{tabular}

Berdasarkan hasil penelitian dapat diketahui bahwa terdapat pengaruh senam prolanis terhadap perubahan tekanan darah sistol dimana didapatkan hasil p-value 0,001 . 
Hasfika Ivonna, Erawati S, Sitorus Friska E : Pengaruh Senam Prolanis Terhadap Pengendalian Kadar Glukosa Darah dan Tekanan Darah Pada Pasien Diabetes Melitus Tipe II dan Hipertensi

Tabel 6. Pengaruh Senam Prolanis terhadap TD Diastol

\begin{tabular}{|l|l|l|l|}
\hline TD Diastol & Mean Difference & $z$ & Sig \\
\hline Pre-Test & 22.50 & $-5,947$ &, 001 \\
Post-Test & & & \\
\hline
\end{tabular}

\section{PEMBAHASAN}

\section{Senam Prolanis Terhadap Perubahan KGD}

Pada Penelitian ini senam prolanis dilakukan 2 kali dalam seminggu, dimana pelaksanaan senam selama 4 minggu. Setiap pelaksanaan senam dilakukan selama 30 menit. Ppengukuran KGD dilakukan pertama kali satu hari sebelum pelaksanaan senam prolanis, dan pengukuran KGD berikutnya dilaksanakan setelah 4 minggu pelaksanaan senam prolanis. Setelah senam prolanis dilakukan rata-rata penurunan KGD adalah 229,37 mq/dl, dimana rata-rata KGD sebelum pelaksanaan senam prolanis adalah 235,29 mq/dl. Latihan fisik yang dilakukan dengan dosis yang tepat dan benar dapat menimbulkan proses yaitu proses adaptasi pada sistem, yaitu sistem saraf, hormon, kardiorespirasi, metabolisme, neuromuskuloskeletal dan ketahanan tubuh. Setelah latihan fisik dilakukan maka selama 10 menit kebutuhan akan glukosa sewaktu akan mengalami peningkatan sampai 15 kali dari jumlah total kebutuhan pada keadaan bisasa. Olahraga yang dilakukan pada penderita DM dapat mengakibatkan terjadinya pemakaian glukosa yang meningkat oleh otot aktif, sehingga secara langsung olahraga tersebut dapat menurunkan glukosa darah (Ilyas, 2015).

\section{Senam Prolanis Terhadap Perubahan Tekanan Darah}

Hasil penelitian ini menunjukkan bahwa rata-rata TD sistol sebelum dilakukannya senam adalah $151,18 \mathrm{mmHg}$ dan rata-rata tekanan darah sistol setelah 4 minggu pelaksanaan senam menjadi 147,51 mmHg. Sedangkan TD diastole sebelum senam dilakukan didapat-kan ratarata yaitu 97,39 $\mathrm{mmHg}$ dan setelah 4 minggu pelaksanaan senam menjadi $89,04 \mathrm{mmHg}$. Pengukuran yang dilakukan terhadap tekanan darah bersamaan dengan pengukuran KGD pasien sebelum dan sesudah dilakukannya senam prolanis. Untuk melihat apakah senam prolanis mempunyai pengaruh terhadap tekanan darah maka dilakukan analisis data dengan menggunakan uji statistik yaitu uji Paired T-Test, hasil analisis yang terdapat pada tekanan darah sistol sebelum dan sesudah perlakuan didapatkan nilai Pvalue $=0,001$. Sedangkan hasil analisis yang didapat pada tekanan darah diastolic sebelum dan sesudah pelaksanaan senam didapatkan nilai Pvalue $=0,000$ artinya Ha diterima pada tekanan darah sistolik maupun diastolik atau terdapat pengaruh senam prolanis terhadap perubahan tekanan darah sistolik maupun diastolik pada responden. Berdasarkan hal diatas dapat disimpulkan dimana perlakuan senam prolanis mampu menurunkan tekanan darah sistolik maupun diastolik pada pasien hipertensi di Puskesmas Aek Habil Kota Sibolga. Senam Prolanis mempunyai pengaruh yang signifikan Terhadap keadaan tekanan darah sistolik dan diastolik pada lansia penderita hipertensi. Lansia yang mengikuti senam prolanis, maka tekanan darah sistolik dan diastolic nya menjadi turun (Lutfiasih \& Nailul, 2018). Senam prolanis meningkatkan kegiatan fisik dan aktivitas olahraga. Kegiatan fisik yang dilakukan secara teratur dapat menurunkan tekanan darah. Kegiatan olahraga dapat menurunkan nilai tekanan darah ratarata 5-7 mmHg. Penurunan tekanan darah setelah berolahraga dapat berlangsung sampai 22 jam (Dalimartha, 2013)Hal ini sejalan dengan Hasa. nudin et al. (2018) dimana aktivitas fisik yang pelaksanaanya kurang dapat mengakibatkan tekanan darah meningkat. 
Hasfika Ivonna, Erawati S, Sitorus Friska E : Pengaruh Senam Prolanis Terhadap Pengendalian Kadar Glukosa Darah dan Tekanan Darah Pada Pasien Diabetes Melitus Tipe II dan Hipertensi

\section{KESIMPULAN}

Kesimpulan dari penelitian ini adalah :

Hasil penelitian yang dilakukan sesuai dengan hasil PERKENI (2015) dimana menyebutkan bahwa kegiatan jasmani yang dilaksanakan setiap hari dan latihan secara beraturan (3 kali seminggu kurang lebih 30 menit) adalah salah satu pilar yang ada dalam pengelolaan DM tipe II. Latihan jasmani yang baik seperti latihan jasmani yang sifatnya aerobik dengan intensitas sedang (50-70\% denyut jantung maksimal) misalnya: jalan dengan cepat, menaiki sepeda dengan santai, jogging, serta berenang. Sama halnya dengan penelitian Hariyanto (2015) menyatakan bahwa olahraga senam dapat dilakukan sebagai manajemen dalam menurunkan gula darah bukan juga hanya untuk mencegah tapi untuk tetap menjaga kesehatan lansia, senam prolanis masih belum efektif, pada intensitas senam hanya dillaksanakan satu kali dalam satu minggu sehingga belum memberikan dampak yang baik terhadap gula darah. Dengan melaksanakan olahraga atau beraktivitas secara rutin dapat meminimalkan atau menstabilkan tekanan darah. Hal ini diperkuat lagi oleh Börjesson et al. (2015) dimana yang ditemukan pada pasien hipertensi respon tekanan darah meningkat mungkin berlebihan setelah selesai pelaksanaan aktivitas senam aerobic, selanjutnya tekanan darah akan tetap berkurang di bawah tekanan darah saat pasien istirahat yang sering disebut dengan hipotensi pasca-latihan. Penurunan tekanan darah bisa berkurang sampai 10-20 $\mathrm{mmHg}$ dan biasanya mampu bertahan setelah latihan. Demikian juga penelitian dengan penelitian Lumempouw, dkk (2016) yang menyatakan bahwa terdapat perbedaan yang bermakna antara tekanan darah sistolik awal dan akhir pada latihan $2 \mathrm{kali} /$ minggu antara tekanan darah diastolik awal dan akhir pada latihan $2 \mathrm{kali} /$ minggu antara tekanan darah sistolik awal dan akhir pada latihan $3 \mathrm{kali} /$ minggu dan antara tekanan darah diastolik awal dan akhir pada latihan $3 \mathrm{kali} /$ minggu.

\section{DAFTAR PUSTAKA}

Afrega A., 2019. Pengaruh senam diabetes mellitus terhadap kadar gula darah pada penderita diabetes mellitus tipe 2 di UPTD Puskesmas Gading Rejo tahun 2019. Skripsi, Sekolah Tinggi Ilmu Kesehatan Muhammadiyah, Pringsewu Lampung.

Aji, W. P. B., Isnaeni, Y., Sugiyanto. 2015. Pengaruh Senam Lansia Terhadap Tekanan Darah Pada Lansia Penderita Hipertensi Di Posyandu Lansia Dusun Banaran 8 Playen Gunungkidul. Jurnal STIKES Aisyiah Yogyakarta

Anggara, Dwi., \& Prayitno, N. 2017. Faktor-Faktor Yang Berhubungan Dengan Tekanan Darah Di Puskesmas Telaga Murni Cikarang Barat. Jurnal Ilmiah Kesehatan, 5(1):1-9

Astuti, D. 2016. Pengaruh Senam Aerobik terhadap Kadar Gula Darah Puasa Penderita Diabetes mellitus Tipe 2 pada Kelompok Prolanis UPT PUSKESMAS Wonogiri I. Surakarta: Stikes Kusuma Husada

Caspersen C, Powell K, Christenson G. Physical activity, exercise, and physical fitness: Definitions and distinctions for health-related research. Public Health Rep. 1985; 100:126-31.

Dhillon PK., Jeemon P., Arora NK., Mathur P., Maskey M., Sukirna RD., Prabhakaran D., 2012. Status of epidemiology in the WHO South-East Asia region: burden of disease, determinants of health and epidemiological research, workforce and training capacity. International Journal of Epidemiology, 41(3): 847 - 860. Desember 02, 2019. https://www.ncbi.nlm.nih.gov/pmc/articles/PMC3396314/

Hariyanto, E. 2015. Hubungan Aktifitas Fisik dengan Kadar Gula Darah Puasa Pada Pasien Diabetes Melitus Tipe-2 di Rumah Sakit Daerah Kota Cilegon. Jakarta: Universitas Islam Negeri Syarif Hidayatullah.

Hasanudin., Ardiyani, V. M., Perwiraaningtyas, P. 2018. Hubungan Aktivitas Fisik Dengan Tekanan Darah Pada Masyarakat Penderita Hipertensi Di Wilayah Tlogosuryo 
Hasfika Ivonna, Erawati S, Sitorus Friska E : Pengaruh Senam Prolanis Terhadap Pengendalian Kadar Glukosa Darah dan Tekanan Darah Pada Pasien Diabetes Melitus Tipe II dan Hipertensi

Kelurahan Tlogomas Kecamatan Lowokwaru Kota Malang. Nursing News Volume 3, Nomor 1.

Horden, M. D., et.al. 2012. Exercise prescription for patients with type 2 diabetes and prediabetes: A position statement from Exercise and Sport Science Australia. Journal of Science and Medicine in Sport, 15, pp. 25-31.

Moniaga, Victor. 2013. Pengaruh Senam Bugar Lansia Terhadap Tekanan Darah Penderita Hipertensi di BPLU Senja Cerah Paniki Bawah. Jurnal e-Biomedik (eBM), Volume 1, Nomor 2, Juli 2013, hlm. 785-789

Nastiti, PH., Hanif A., 2018. Hubungan senam prolanis terhadap kadar gula puasa dan KGD2PP pada pasien DM tipe 2. Proceeding APKKM ke-6 FK Universitas Muhammadiyah Surakarta,: 36 - 41.

Rismayanthi C. Pengaruh Latihan Senam Jantung Indonesia Terhadap Penurunan Tekanan Darah pada Penderita Hipertensi [Tesis]. Yogyakarta: Pps IK UNY, 2009.

Rosdiana AI., Raharjo BB., Indarjo S., 2017. Implementasi program pengelolaan penyakit kronis (Prolanis). Higeia Journal of Public Health Research and Development, 1(3): $140-150 . \quad$ Desember $\quad 02, \quad 2019$. https://journal.unnes.ac.id/sju/index.php/higeia/issue/view/1114

Soelistijo SA., Novida H., Rudijanto A., Soewondo P., et al., 2015. Konsensus pengelolaan dan pencegahan Diabetes Melitus Tipe 2 di Indonesia 2015. Jakarta: PB PERKENI.

Trisnawati SK., Setyorogo S., 2013. Faktor risiko kejadian Diabetes Melitus Tipe II di Puskesmas Kecamatan Cengkareng Jakarta Barat Tahun 2012. Jurnal Ilmiah Kesehatan, 5(1): 6 - 11. Desember 02, 2019. http://fmipa.umri.ac.id/wpcontent/uploads/2016/06/YUNI-INDRI-FAKTOR-RESIKO-DM.pdf.

\begin{tabular}{|l|l|l|l|}
\hline Accepted Date & Revised Date & Decided Date & Accepted to Publish \\
\hline 12 November 2020 & 13 November 2020 & 19 November 2020 & Ya \\
\hline
\end{tabular}

